\title{
Cytokines and the regulation of tolerance
}

\author{
James L.M. Ferrara
}

Commentary

See related article,

pages 1125-1132.

Departments of Internal Medicine and Pediatrics, University of Michigan Cancer Center, CGC6308, 1500 East Medical Center Drive, Ann Arbor, Michigan 48109-0942, USA. Phone: (734) 615-1340;

Fax: (734) 615-3947; E-mail: ferrara@umich.edu.

Vigorous debates abound in the literature regarding the regulation of the immune responses and the induction of tolerance, a process critical to the understanding of the rejection of solid organ grafts, graft versus host disease, and autoimmune disorders. Tolerance comes in two forms: In central tolerance, $\mathrm{T}$ cells that respond to a specific antigen are deleted in the thymus before emigrating to the "periphery" or systemic circulation. Peripheral tolerance, on the other hand, refers to the regulation or suppression of mature lymphocytes that are already in circulation. In the past several years, much attention has focused on the role of $\mathrm{T}$ cells of different subtypes and the significance of various cytokines in generating tolerance, especially the peripheral form (1).

Although both $\mathrm{CD}^{+}$and $\mathrm{CD}^{+} \mathrm{T}$ cells secrete cytokines, $\mathrm{CD}^{+}$cells secrete them in significantly larger quantities (hence, the $\mathrm{T}$ "helper" [Th] nomenclature). $\mathrm{CD}^{+} \mathrm{T}$ cells can be further subdivided by the patterns of cytokine released: Th1 cells produce IL- 2 and IFN- $\gamma$, which are critical to cell-mediated immunity, whereas Th2 cells produce IL-4, IL-5, and IL-10, which promote antibody production and humoral immunity (2). When naive $T$ cells first exit the thymus, they can secrete both Th1 and Th2 cytokines and are termed Th0, but as these cells encounter antigen and become memory cells, their cytokine patterns become fixed as either Th1 or Th2. Responses by a given T-cell clone to a particular antigen tend to fall into one or the other pattern (3), especially in rodents, in which $\mathrm{T}$-cell responses are more rigidly fixed than in humans. The exclusive expression of Th1 and Th2 responses arises in part because these T-cell subtypes suppress each other's function $(4,5)$. This cross-regulation has given rise to the "Th1/Th2" paradigm, in which a dominance of proinflammatory Th1 cytokines causes destruction of target tissues and a loss of tolerance, whereas the dominance of Th2 cytokines suppresses the Th1 response and promotes tolerance (6-11).

As with many paradigms, the simplicity of Th1/Th2 dichotomy is both its strength and its weakness. This model appears to describe many responses to foreign cells and proteins, but anomalies have been noted, and the study by Coudert and colleagues in this issue of the JCI (12) provides an example of a Th2 cytokine response that activates humoral immunity but does not engender tolerance. Indeed, these investigators show that an enhanced Th2 (and presumably tolerant) response to foreign cells eventually leads to lethal autoimmune disease. They used a

In the past several years,
much attention has focused on the role
of various subtypes of T cells and the
significance of various cytokines in gen-
erating tolerance. .

model of neonatal tolerance in which cells from semiallogeneic $F_{1}$ hybrid donors are injected into newborns of one of the homozygous parental strains. The cells are not rejected by the newborn animals, as they would be by adult animals but, rather, persist for months, producing a state of mixed chimerism. This tolerant state is characterized by a Th2 response of the host, and if IL- 4 is neutralized or eliminated in vivo, the host generates $\mathrm{CD}^{+}$cytolytic $\mathrm{T}$ lymphocytes (CTLs) that reject the donor cells $(13,14)$. Tolerance in this case is not complete, because host lymphocytes do eventually attack that eliminate the donor cells, usually within 10 weeks.

According to the Th1/Th2 paradigm, if some Th2 response is good for tolerance, more Th 2 would be expected to be better. To enhance the Th2 response,
Coudert et al. used recipient mice lacking $\beta_{2}$ microglobulin $\left(\beta_{2} \mathrm{~m}\right)$ to further reduce the rejection of donor cells. Because they are deficient in $\beta_{2} \mathrm{~m}$-an invariant component of the class I MHC whose absence prevents MHC I expression on the cell surface-these animals are substantially depleted for $\mathrm{CD}^{+}$cells, which depend on antigen presentation through MHC I for their development and activation. Small numbers of $\mathrm{CD}^{+}$ cells can persist in $\beta_{2}{ }^{-1-}$ mice, but the investigators used $\beta_{2} m^{-1-}$ mice both as donors and recipients to eliminate $\mathrm{CD}^{+}$cells completely from the system. The result was indeed an increased Th2 response of host cells and an increased persistence of donor B cells. This Th2 activity was not associated with tolerance, however, but rather an increased antibody secretion of donor B cells that caused major damage to visceral organs and that proved lethal in the majority of animals. The increased Th2 cytokines also stimulated eosinophil production and resulted in an autoimmune syndrome that resembles idiopathic hypereosinophilia, which is associated with increased production of IL-5 (15). Thus, Th2 secretion that was unchecked by $\mathrm{CD}^{+}$cells created a lethal expansion and activation of autoreactive $B$ cells and eosinophils. Production of the important regulatory cytokine IL-10 was also increased in sick animals, ruling out its absence as an explanation for the decreased tolerance. It is possible that, a subset that produced only IL-10 (5) or another suppressive cytokine, such as TGF- $\beta$ (16), might regulate the process but such a restricted, suppressive response was not observed in these experiments.

The findings of Coudert et al. (12) show the absence of MHC I results in an uncontrolled Th2 response and subsequent autoimmune disease. The authors do not directly test the block- 
ade or absence of $\mathrm{CD}^{+}$cell function, and thus the formal possibility of indirect generation of autoimmune disease by the absence of MHC I must be acknowledged, but the most likely explanation is that $\mathrm{CD}^{+}$cells derived from the host serve as crucial regulators of the host Th2 response in this system, as donor $\mathrm{F}_{1} \mathrm{~T}$ cells are tolerant of parental host antigens. Regulatory $\mathrm{CD}^{+}$cells are critical to the generation and maintenance of tolerance in many systems (1), and the mechanisms by which they regulate this effect could be multiple. As the authors note in their discussion, these $\mathrm{CD}^{+}$CTLs could eliminate donor APC and prevent the chronic activation of $\mathrm{CD}^{+}$ cells. Alternatively, $\mathrm{CD}^{+}$cells might regulate $\mathrm{CD}^{+}$cells directly by secreting IFN- $\gamma$, which reduces Th 2 cytokine production. To the extent that B cells function as APC in this system, IFN- $\gamma$ may act by both the above mechanisms because IFN- $\gamma$ is directly toxic to B cells (17). Ultimately it is likely that no sin- gle mechanism will account for all of tolerance and that the balance of both cytokine networks and regulatory cells operate in this important aspect of immunological homeostasis.

1. Zhai, Y., and Kupiec-Weglinski, J. 1999. What is the role of regulatory $\mathrm{T}$ cells in transplantation tolerance? Curr. Opin. Immunol. 11:497-503.

2. Mosmann, T.R., and Coffman, R.L. 1989. TH1 and TH 2 cells: different patterns of lymphokine secretion lead to different functional properties. Annu. Rev. Immunol. 7:145-173.

3. Fiorentino, D.F., Bond, M.W., and Mosmann, T.R 1989. Two types of mouse T helper cells. IV. Th2 clones secrete a factor that inhibits cytokine production by Th 1 clones. J. Exp. Med. 170:2081-2095.

4. Adachi, M., Oda, N., Kokubu, F., and Minoguchi, K. 1999. IL-10 induces a Th2 cell tolerance in allergic asthma. Int. Arch. Allergy Immunol. 118:391-394.

5. Groux, H., et al. 1997. A CD4 ${ }^{+}$T cell subset inhibits antigen specific $\mathrm{T}$ cell responses and prevents colitis. Nature. 389:737-742.

6. Ferrara, J., and Krenger, W. 1998. Graft-versushost disease: the influence of type 1 and type $2 \mathrm{~T}$ cell cytokines. Transfus. Med. Rev. 12:1-17.

7. Romball, C., and Weigle, W. 1999. Cytokines in the induction and circumvention of peripheral tolerance. J. Interferon Cytokine Res. 19:671-678.

8. Punch, J., Tono, T., Qun, L., Bishop, D., and Bromberg, J. 1998. Tolerance induction by anti-
CD2 plus anti-CD3 monoclonal antibodies: evidence for an IL-4 requirement. J. Immunol. 161:1156-1162.

9. Bushell, A., Niimi, M., Morris, P., and Wood, K. 1999. Evidence for immune regulation in the induction of transplantation tolerance: a conditional but limited role for IL-4. J. Immunol. 162:1359-1366.

10. Modlin, R. 1994. Th1-Th2 paradigm: insights from leprosy. J. Invest. Dermatol. 102:828-832.

11. Lee, P.P., et al. 1997. T helper 2-dominant antilymphoma immune response is associated with fatal outcome. Blood. 90:1611-1617.

12. Coudert, J., et al. 2000. Lethal host-versus-graft disease and hypereosinophilic in the absence of MHC I-T-cell interactions. J. Clin. Invest. 105:1125-1132.

13. Schurmans, S., et al. 1990. In vivo effects of anti-IL-4 monoclonal antibody on neonatal induction of tolerance and on associated autoimmune syndrome. J. Immunol. 145:2465-2473.

14. Donckier, V., et al. 1998. IL-12 prevents neonatal induction of transplantation tolerance in mice. Eur. J. Immunol. 28:1426-1430.

15. Rothenberg, M. 1998. Eosinophilia. N. Engl.J. Med. 338:1592-1600.

16. Weiner, H., et al. 1994. Oral tolerance: immunologic mechanisms and treatment of animal and human organ-specific diseases by oral administration of autoantigens. Annual Reviews Inc. Palo Alto, California, USA. 8009-8037.

17. Reynolds, D., Boom, W., and Abbas, A. 1987. Inhibition of B lymphocyte activation by interferongamma. J. Immunol. 139:767-773. 